\title{
Implementing Software Process Improvement Initiatives: An Empirical Study
}

\author{
Mahmood Niazi ${ }^{a}$, David Wilson ${ }^{b}$ and Didar Zowghi ${ }^{b}$ \\ ${ }^{a}$ School of Computing and Mathematics, Keele University, ST5 5BG, UK \\ mkniazi@cs.keele.ac.uk \\ ${ }^{\mathrm{b}}$ Faculty of Information Technology, University of Technology Sydney, NSW 2007, \\ Australia \\ \{davidw,didar\}@it.uts.edu.au
}

\begin{abstract}
In this paper we present findings from our empirical study of software process improvement (SPI) implementation. We aim to provide SPI practitioners with insight into designing appropriate SPI implementation initiatives in order to achieve better results. Thirty-four interviews were conducted with Australian practitioners. Three SPI implementation issues were investigated: reasons for embarking on SPI initiatives, SPI benefits to the management, and factors that play a positive role in SPI implementation.

We have found that most common reasons for embarking on SPI initiatives are to: improve the quality of software developed, reduce software development cost, and increase productivity. Our results show that $71 \%$ of the practitioners said that SPI initiatives provided clear benefits to the management. We have also found that most frequently cited SPI implementation factors are: SPI awareness, defined SPI implementation methodology, experienced staff, staff time and resources, senior management commitment and training.

Our aim of conducting this study is to provide a SPI implementation framework for the design of effective SPI implementation initiatives.
\end{abstract}

\section{Introduction}

Information Technology failure has been a common topic in the literature over the last 25 or more years with the annual CHAOS Report [1] perhaps being the most cited regular report. These failures are often seen as being due to issues of software quality, which has accordingly received much attention in both academia and industry. Software quality problems are widely acknowledged to affect the development cost and time $[1 ; 2]$. A recent study, conducted by a group of Fellows of the Royal Academy of Engineering and British Computer Society, shows that despite spending 22.6 billions pounds on IT projects in UK during 2003/2004, significant numbers of projects still fail to deliver key benefits on time and to target cost and specification [3]. In addition to such disappointing performance, some software projects result in operational failure (e.g. Airbus A320 [4], the London Ambulance Service [5], and the explosion of the Ariane 5 [6]) or even the demise of organisations (e.g. Greyhound's 
TRIPS System [7], FoxMeyer's ERP project [8], Oxford Health's 'computer glitch' [9] and One.Tel billing system [10]).

There have been increasing calls for the software industry to find solutions to software quality problems [11]. Software developing organizations are realizing that one of their fundamental challenges is to effectively manage the software development process $[12 ; 13]$. In order to address the effective management of software process different methods have been developed, of which Software Process Improvement (SPI) is the one mostly used.

Different advances have been made in the development of SPI standards and models, e.g. CMM, CMMI, and ISO's SPICE. Despite the significant development of standards and models for SPI, the failure rate for SPI programmes is high. The recent report from the Software Engineering Institute puts the rate of failure at around $70 \%$ [14]. This may be due to the fact that not enough attention has been paid to SPI implementation issues.

In this paper we present empirical findings of a study into SPI implementation that points to the issues that have to be addressed when developing SPI implementation initiatives. Our study uses data from interviews of 34 Australian practitioners in 29 Australian companies. The objective of this paper is to provide insight to SPI practitioners into designing appropriate SPI implementation initiatives in order to achieve better results. Our overall aim of this study is to develop a SPI implementation framework in order to guide practitioners in designing effective SPI implementation strategies.

There are four research questions that have motivated our work:

RQ1. Why different companies embark on SPI initiatives?

RQ2. Have SPI initiatives provided clear and expected benefits to the management?

RQ3. What factors, as identified by mature companies, have a positive impact on SPI implementation?

RQ4. What factors, as identified by immature companies, have a positive impact on SPI implementation?

This paper is organised as follows. Section 2 describes the background. Section 3 describes the research design. In Section 4 findings are presented and analysed. Discussion is provided in Section 5. Section 6 provides the conclusion.

\section{Background}

McDermid and Bennet [15] have argued that the human factors in SPI have been largely ignored and this has damaged the effectiveness of SPI implementation programmes. Hall and Wilson [16; 17] have also suggested that the experiences, opinions and perceptions of software practitioners impact indirectly on the quality of software produced. This also implies that such attributes influence how software practitioners behave towards SPI implementation approaches. It is, therefore, very important to identify the views and perceptions of different practitioners about factors that play a positive role in the implementation of SPI initiative. These views, experiences and perceptions collectively may provide practitioners with sufficient knowledge about the nature of issues that play a positive role in the implementation of 
SPI programmes in order to assist them in effectively planning SPI implementation strategies.

Since the introduction of Capability Maturity Model, a number of related studies have been conducted to identify SPI factors [18-22]. Following is a summary of some of the well known studies.

- A survey of 138 individuals in 56 software organizations [18] identified the factors necessary for implementing a successful SPI programme. The authors have identified a number of factors associated with successful SPI programmes. In this study factors associated with unsuccessful SPI programmes are also identified [18].

- A review of 56 software organizations that have either implemented an ISO 9000 quality system or that have conducted a CMM-based process improvement initiative, determined ten factors that affect organizational change in SPI [19].

- El Emam et al. [20] have investigated some of the important success factors and barriers for SPI. This study is a follow-up study to [18]. They have used data from 14 companies involved in the SPICE trials in order to identify which of the factors are most strongly related to the success of SPI efforts and which factors have no impact.

- A questionnaire survey of 85 UK companies [21] identified the key success factors that can impact SPI implementation. The results show that the four factors that practitioners considered had a major impact on successfully implementing SPI. These factors are: reviews, standards and procedures, training and mentoring and experienced staff. The authors have also identified four further factors (internal leadership, inspections, executive support and internal process ownership) that more mature companies considered had a major impact on successfully implementing SPI.

Many of the studies mentioned above have adopted the questionnaire survey method for the identification of factors. A disadvantage of the questionnaire survey method is that respondents are provided with a list of possible factors and asked to select from that list. This tends to pre-empt the factors investigated and to limit them to those reported in existing studies - respondents only focus on the factors provided in the list. In order to provide more confidence in the study it is important that practitioners' experiences and perceptions should be explored independently and without any suggestion from the researcher. So this motivated us to use interviews for data collection in this study.

The work reported in some of the other studies is based on single case study. This type of work has been assessed for being company-specific and therefore potentially unrepresentative [23]. In our study, we not only conducted 34 interviews, but data was collected as an impartial third party.

\section{Study Design}

In order to address research questions, we collected and analysed empirical data using a combination of qualitative and quantitative methods. Qualitative and quantitative 
methods are complementary [24]. Qualitative data can be converted through coding to become frequency data, and hence quantitative [25; 26]. Seaman [26] adds that although this process of coding transforms qualitative data into quantitative data, it does not affect its subjectivity or objectivity. Bryman [27] noted that reverse can also occur. One of the examples in which quantitative research can facilitate qualitative research is by the selection of case studies for further research.

This overview of methods indicates that empirical methods help researchers move towards well-founded decisions [28]. In line with recommendations, this research uses a combination of qualitative and quantitative methods for data collection and analysis.

\subsection{Sample profile}

From November 2002 to August 2003 we visited 29 software companies and conducted 34 interviews. The sample profile is shown in Appendix A. All of the 29 companies responded to a request for participants which was posted via the email. The target population in this research was those software-producing companies that have initiated SPI programmes. Although we do not claim this is a statistically representative sample, appendix A does show that companies in the study range from a very small software house to very large multinational companies and cover a wide range of application areas. It is further important to acknowledge that the data was collected from companies who were tackling real issues on a daily basis; therefore we have high confidence in the accuracy and validity of data [29].

It is important to acknowledge that the practitioners sampled within companies are representative of practitioners in organisations as a whole. A truly representative sample is impossible to attain and the researcher should try to remove as much of the sample bias as possible [30]. The sample of practitioners researched includes developers, business analysts, methodology analyst, technical directors, project managers and senior management.

\subsection{Data collection method}

Interviews were conducted with three groups of practitioners: developers, project managers and senior managers. Questioning was both open and close-ended with frequent probing to elaborate and clarify meaning. The negotiated interview duration was half an hour, however, the researcher and interviewee would determine the pace of the interview. Before the interview the researcher arranged the time and place with which the interviewees were comfortable. Most of the interviews took place in the interviewee's offices.

\subsection{Data analysis method}

This research seeks to identify perceptions and experiences of practitioners about SPI implementation. In order to identify common themes for the implementation of SPI programmes, the following process has been adapted in this research [25; 29]: 
- Identifying themes for SPI implementation from transcripts: All the interview transcripts were read to identify the major themes for SPI implementation. These themes were noted down and compared to the notes made during the interviews in order to reassure that the transcripts being analysed are indeed a true reflection of the discussion in the interviews. These two process steps also verify that the transcription process has not changed the original data generated in the interviews.

- Generate categories: All the interview transcripts were read again to generate categories for responses. Different themes were grouped together under different categories. For example, budget, funds etc were grouped together under critical success factor (CSF) category "resources". Each category represents a CSF for the implementation of SPI programme.

In order to reduce researcher's bias we conducted inter-rater reliability in this process. Three interview recordings were selected at random and a colleague, who was not familiar with the issues being discussed, was asked to identify CSFs that appeared in the interviews. The results were compared with our previous results and no disagreements were found.

\section{Findings}

In this section we discuss the results relating to RQ1 to RQ5.

\subsection{Reasons for embarking on an SPI initiative}

In order to answer RQ1, Table 1 shows a list of reasons for embarking on SPI initiatives. The percentage shows the proportion of practitioners that cited a particular reason.

It shows that most of the practitioners want to improve the quality of software. Nearly half of the practitioners embark on SPI initiative to reduce the development cost and to increase productivity. It shows that practitioners are interested to reduce time-to-market and to shorten software development cycle times. Table 1 also shows that few companies introduced SPI initiatives because of marketing purpose.

\subsection{Clear and expected benefits of an SPI initiative}

Table 2 shows that $71 \%$ of the practitioners say that SPI initiatives provided clear and expected benefits to the management. Only $6 \%$ of the practitioners say SPI initiatives did not provide any benefits to the management. Our results are in line with other studies that showed that the effort put into SPI can assist in producing high quality software, reducing cost and time, and increasing productivity [12; 13; 31-33]. 
Table 1 Embarking reasons

\begin{tabular}{lll}
\hline Reasons for embarking on SPI initiatives & \multicolumn{2}{c}{$\begin{array}{l}\text { Occurrence } \\
\text { interviews n=34 }\end{array}$} \\
\cline { 2 - 3 } & Freq & in \\
\hline To improve the quality of the software developed & 26 & 77 \\
To reduce software development cost & 17 & 50 \\
To increase productivity & 16 & 47 \\
To reduce time-to-market & 12 & 35 \\
To shorten software development cycle times & 9 & 27 \\
To improve management visibility & 8 & 24 \\
For public relations/ marketing purposes & 6 & 18 \\
To automate the production of relevant development & 4 & 12 \\
documentation & & \\
To meet vendor/supplier qualification & 3 & 9 \\
To make procedures and processes optimal & 3 & 9 \\
CEO directive & 2 & 6 \\
Industry requirements & 2 & 6 \\
To bring discipline to the company & 2 & 6 \\
Desire to change & 1 & 3 \\
To reduce maintenance & 1 & 3 \\
To reduce risks & 1 & 3 \\
\hline
\end{tabular}

Table 2 Expected SPI benefits

\begin{tabular}{llccc}
\hline $\begin{array}{l}\text { Clear and expected benefits to the } \\
\text { management }\end{array}$ & & \multicolumn{2}{c}{$\begin{array}{c}\text { Occurrence in interviews } \\
\mathbf{n = 3 4}\end{array}$} \\
\cline { 2 - 4 } & & Freq & $\%$ \\
\hline Yes & 24 & 71 \\
No & 2 & 6 \\
Do not know & 8 & 23 \\
Total & 34 & 100 \\
\hline
\end{tabular}

\subsection{Mature verses immature companies}

We partitioned the 29 companies according to their appraisal status. Each company was either formally appraised, informally appraised (self rated) or no appraisal. In this research, the companies that have been assessed (formally or informally) to be in CMM level-2 or above are considered mature companies. Similarly, the companies with ISO 9001 certification are also considered to be mature companies. We have collapsed a sample of companies with CMM level-2 and above with a sample of companies with ISO 9001 certification. 
The companies that did not achieve CMM level-2 or ISO 9001 certification are considered to be immature companies. Similarly, the companies that are using some internal methodologies for software development but they did not provide any appraisal information are considered to be immature companies.

In order to answer RQ3, Table 3 shows the list of critical success factors (CSFs) cited in the empirical study. The most frequently cited factor by mature companies is training and mentoring, i.e. 79\%. This suggests that in practitioners' opinion training can play a vital role in the implementation of SPI programs. Other frequently cited factors by mature companies are senior management commitment $(71 \%)$ and SPI awareness $(64 \%)$. It shows that practitioners of mature companies consider management commitment and awareness of the benefits of SPI programs imperative for the successful implementation of SPI initiatives. The results also show that defined SPI implementation methodology, experience staff and staff time and resources are also important factors.

Table 3 Mature and immature companies

\begin{tabular}{|c|c|c|c|c|}
\hline \multirow[t]{2}{*}{ Success Factors } & \multicolumn{2}{|c|}{$\begin{array}{l}\text { Mature } \\
\text { companies } \\
(n=14)\end{array}$} & \multicolumn{2}{|c|}{$\begin{array}{l}\text { Immature } \\
\text { companies } \\
(n=20)\end{array}$} \\
\hline & Freq & $\%$ & Freq & $\%$ \\
\hline Company culture & 2 & 14 & 0 & 0 \\
\hline Creating process action teams/external agents & 1 & 7 & 1 & 5 \\
\hline Customer satisfaction & 1 & 7 & 1 & 5 \\
\hline Defined SPI implementation methodology & 6 & 43 & 6 & 30 \\
\hline $\begin{array}{l}\text { Encouraging communication and } \\
\text { collaboration }\end{array}$ & 4 & 29 & 1 & 5 \\
\hline Experienced staff & 6 & 43 & 7 & 35 \\
\hline Facilitation & 2 & 14 & 7 & 35 \\
\hline Formal documentation & 1 & 7 & 2 & 10 \\
\hline $\begin{array}{l}\text { Formalised relationship between development } \\
\text { team }\end{array}$ & 0 & 0 & 1 & 5 \\
\hline Higher staff moral & 1 & 7 & 0 & 0 \\
\hline Logical sequence/order of SPI implementation & 1 & 7 & 1 & 5 \\
\hline Managing the SPI project & 2 & 14 & 3 & 15 \\
\hline Measurement & 2 & 14 & 0 & 0 \\
\hline Quality assurance & 2 & 14 & 3 & 15 \\
\hline Reviews & 1 & 7 & 2 & 10 \\
\hline Senior management commitment & 10 & 71 & 13 & 65 \\
\hline SPI Awareness & 9 & 64 & 11 & 55 \\
\hline Staff involvement & 3 & 21 & 8 & 40 \\
\hline Staff time and resources & 5 & 36 & 11 & 55 \\
\hline Tailoring improvement initiatives & 2 & 14 & 0 & 0 \\
\hline Training and mentoring & 11 & 79 & 12 & 60 \\
\hline Tools/packages & 0 & 0 & 2 & 10 \\
\hline
\end{tabular}


In order to answer RQ4, Table 3 shows the list of CSFs cited in the empirical study. Table 3 shows that the most frequently cited factor by immature companies is senior management commitment, $65 \%$. The factor training and mentoring is cited by $60 \%$ of practitioners. The results show that most of the practitioners of immature companies consider SPI awareness and resources critical for the implementation of SPI. The results also suggest that practitioners want their involvement in SPI initiatives. They also want experience staff and an SPI implementation methodology. The practitioners of immature companies also require facilitation during SPI implementation process.

\section{Discussion}

Table 4 shows that SPI approach is strongly established in many companies. Only a $6 \%$ of companies say SPI is less than one year old and $56 \%$ say it has been in operation for more than five years. These results show that companies have been using SPI approach over a relatively long period of time. Despite this, less companies in this study report high software process maturity (i.e. 14 out of 29). Companies in our sample seem to be accelerating SPI as slow as has been reported in SEI [34]:

- Maturity level 1 to 2 is 22 months

- Maturity level 2 to 3 is 19 months

- Maturity level 3 to 4 is 25 months

- Maturity level 4 to 5 is 13 months

Our results suggest that the most frequently cited reasons for embarking on SPI initiatives are to: improve quality of product, reduce cost, increase productivity and reduce time-to-market.

Our results also suggest that the most frequently cited factors by mature and immature companies are: training, senior management commitment and SPI awareness. However, comparison of the CSFs in the two data sets provides evidence that there are more similarities than differences between the findings of two sets (as shown in Table 3).

CSFs represent few key areas where management should focus their attention in order to successfully achieve the desire results [35]. In order to decide criticality of a factor, we have used the following criteria:

- If a factor is cited by the respondents in the interviews with a frequency percentage of $>=30 \%$ ) then we treat that factor as a critical factor in this empirical study

A similar approach has been used by other researchers [21]. However, instead of having 50\% limit in this criteria, which is the more common approach, we have reduced this limit to $30 \%$. This is because we wanted to have a sufficient number of implementation factors and with a 50\% limit the identified implementation factors were not sufficient for the required research project. Our ultimate aim was to utilize these common factors in the development of the SPI implementation framework [36; 37].

Using this criterion, six factors from mature companies have been identified that are generally considered critical for successfully implementing SPI. These factors are: 
training and mentoring, higher management support, SPI awareness, defined SPI implementation methodology, experienced staff and staff time and resources.

Using this criterion, eight factors from immature companies have been identified. These factors are: higher management support, training and mentoring, SPI awareness, staff time and resources, staff involvement, experienced staff, facilitation and defined SPI implementation methodology.

Six factors are common between two data sets. The results suggest that companies should focus on these common CSFs in order to successfully implement SPI programs because we have more confidence that a factor does indeed have an impact on SPI implementation if it is critical in both data sets.

Table 4 SPI life

\begin{tabular}{lcc}
\hline \multirow{2}{*}{$\begin{array}{l}\text { How long has your process improvement } \\
\text { programme been in operation? }\end{array}$} & \multicolumn{2}{c}{$\begin{array}{c}\text { Occurrence in interviews } \\
\mathbf{n}=\mathbf{3 4}\end{array}$} \\
\cline { 2 - 3 } & Freq & $\%$ \\
\hline Less than 1 year & 2 & 6 \\
1 - 2 years & 6 & 18 \\
3 - 5 years & 7 & 20 \\
More than 5 years & 19 & 56 \\
Total & 34 & 100.0 \\
\hline
\end{tabular}

\section{Conclusion}

We report on findings from our recent empirical study of SPI implementation with thirty-four Australian practitioners. We aim to provide SPI practitioners with some insight into designing appropriate SPI implementation initiatives in order to achieve better results. Our ultimate aim of conducting this empirical study is to develop a SPI implementation framework in order to assist practitioners in the design of effective SPI implementation strategies. We analysed the experiences, opinions and views of practitioners in order to identify issues that have some impact on the implementation of a SPI programs. We identified the important reasons for embarking on SPI initiatives. We also identified factors that are critical for successful implementation of SPI efforts. Our results provide advice to SPI practitioners on what needs to be addressed when developing SPI implementation initiatives. We have summarised our results in Table 5.

Our findings generally indicate that SPI is progressing in the Australian software industry. It shows that more than half of the companies said that SPI has been in operation for more than five years. However, companies in our sample are not maturing at a reasonable speed. Overall, mature and immature companies showed a good understanding of factors that can play a positive role in the implementation of SPI initiatives. There are more similarities than differences in CSFs identified by two 
types of companies. It shows that these companies are aware of what is imperative for successful implementation of SPI initiatives.

Table 5. Summary of results

\begin{tabular}{|c|c|}
\hline Research Question & Answer \\
\hline $\begin{array}{l}\text { RQ1. Why different companies } \\
\text { embark on SPI initiatives? }\end{array}$ & $\begin{array}{l}\text { Our results suggest that the most frequently } \\
\text { cited reasons for embarking on SPI } \\
\text { initiatives are to: } \\
\text { - } \quad \text { improve quality of product } \\
\text { - } \quad \text { reduce cost } \\
\text { - } \quad \text { increase productivity } \\
\text { reduce time-to-market }\end{array}$ \\
\hline $\begin{array}{l}\text { RQ2. Have SPI initiatives } \\
\text { provided clear and expected } \\
\text { benefits to the management? }\end{array}$ & $\begin{array}{l}\text { Our results show that } 71 \% \text { of the } \\
\text { practitioners say that SPI initiatives provided } \\
\text { clear and expected benefits to the } \\
\text { management. Only } 6 \% \text { of the practitioners } \\
\text { say SPI initiatives did not provide any } \\
\text { benefits to the management }\end{array}$ \\
\hline $\begin{array}{l}\text { RQ3. What factors, as } \\
\text { identified by mature } \\
\text { companies, have a positive } \\
\text { impact on implementing } \\
\text { SPI? }\end{array}$ & 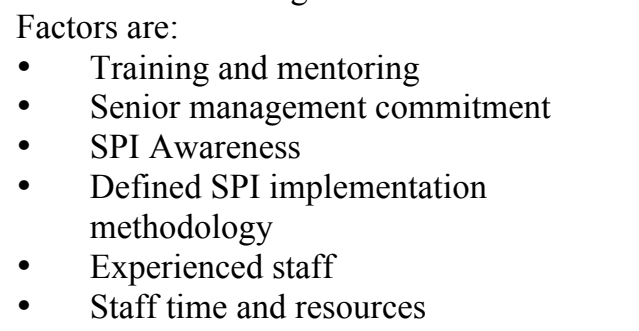 \\
\hline $\begin{array}{l}\text { RQ4. What factors, as } \\
\text { identified by immature } \\
\text { companies, have a positive } \\
\text { impact on implementing } \\
\text { SPI? }\end{array}$ & $\begin{array}{ll}\text { Factors are: } \\
\text { - } & \text { Senior management commitment } \\
\text { - } & \text { Training and mentoring } \\
\text { - } & \text { SPI Awareness } \\
\text { - } & \text { Staff time and resources } \\
\text { - } & \text { Experienced staff } \\
\text { - } & \text { Facilitation } \\
\text { - } & \text { Defined SPI implementation } \\
& \text { methodology }\end{array}$ \\
\hline
\end{tabular}

\section{References}

1 Standish-Group: Chaos - the state of the software industry. (2003).

2 Standish-Group: Chaos - the state of the software industry. Standish group international technical report, 1-11. (1995).

3 The-Royal-Academy-of-Engineering: The Challenges of Complex IT Projects, The report of a working group from The Royal Academy of 
Engineering and The British Computer Society. ISBN 1-903496-15-2 (2004).

Randell, B.: Airbus A320, The Risks Digest: Forum on Risks to the Public in Computers and Related Systems 8 (57). (1989)

5 Finkelstein, A.: Report of the Inquiry Into The London Ambulance Service. International Workshop on Software Specification and Design Case Study Electronic: $\quad$ http://www.cs.ucl.ac.uk/staff/A.Finkelstein/las/lascase0.9.pdf: Site visited 4-3-2003, 1993. (1993)

6 Lions, J. L.: http://www.ima.umn.edu/ arnold/disasters/ariane5rep.html, Site visited 4-3-2003. (1997).

7 Tomsho, R.: Real Dog: How Greyhound Lines Re-Engineered Itself Right Into A Deep Hole, Wall Street Journal 20 (October). (1994) A1-A6.

8 Scott, J., E: The FoxMeyer Drugs' Bankruptcy: Was it a Failure of ERP? In Proc. of the Association for Information Systems 5th Americas Conference on IS, Milwaukee, WI, August. (1999) 223-225.

9 Khasru, B., Z: Former Oxford Health Directors Settle Lawsuit, Fairfield County Business Journal, Stamford. (2nd July). (2001) 5.

10 Paul, B.: On for young and old as James and Kerry began to fret. The Sydney Morning Herald. http://www.smh.com.au/articles/2002/03/20/Pbonetel.htm: Site visited 12-92003 (2002).

11 Crosby, P.: Philip Crosby's reflections on quality. McGraw-Hill.(1996).

12 Pitterman, B.: Telcordia Technologies: The journey to high maturity, IEEE Software (July/August). (2000) 89-96.

13 Yamamura, G.: Software process satisfied employees, IEEE Software (September/October). (1999) 83-85.

14 SEI: Process maturity profile of the software community. Software Engineering Institute, Carnegie Mellon University, (2002).

15 McDermid, J. and Bennet, K.: Software Engineering research: A critical appraisal, IEE Proceedings on software engineering 146 (4). (1999) 179-186.

16 Hall, T. and Wilson, D.: Views of software quality: a field report, IEEE Proceedings on Software Engineering 144 (2). (1997)

17 Hall, T. and Wilson, D.: Perceptions of software quality: a pilot study, Software quality journal (7). (1998) 67-75.

18 Goldenson, D. R. and Herbsleb, J. D.: After the appraisal: A systematic survey of Process Improvement, Its benefits, And Factors That Influence Success. SEI, CMU/SEI-95-TR-009 (1995).

19 Stelzer, D. and Werner, M.: Success factors of organizational change in software process improvement, Software process improvement and practice 4 (4). (1999)

20 El-Emam, K., Fusaro, P. and Smith, B.: Success factors and barriers for software process improvement. Better software practice for business benefit: Principles and experience, IEEE Computer Society (1999)

21 Rainer, A. and Hall, T.: Key success factors for implementing software process improvement: a maturity-based analysis, Journal of Systems \& Software (62). (2002) 71-84. 
22 Rainer, A. and Hall, T.: A quantitative and qualitative analysis of factors affecting software processes, Journal of Systems \& Software, Accepted awaiting publication (2002)

23 Herbsleb, J. D. and Goldenson, D. R.: A systematic survey of CMM experience and results. 18th international conference on software engineering (ICSE-18). Germany (1996) 323-330.

24 Walker, R., Briand, L., Noktin, D., Seaman, C. and Tichy, W.: Panel: Empirical validation - what, why, when, and how. Proceedings of the 25th International Conference on Software Engineering (ICSE '03). (2003)

25 Burnard, P.: A method of analysing interview transcripts in qualitative research, Nurse education today (11). (1991) 461-466.

26 Seaman, C.: Qualitative methods in empirical studies of software engineering, IEEE Transactions on Software Engineering 25 (4). (1999) 557572.

27 Bryman, A.: Quantity and quality in social research. London, Routledge.(1996).

28 Perry, D., Porter, A. and Votta, L.: Empirical studies of software engineering: a roadmap. Proceedings of the Twenty-second Conference on Software Engineering. Ireland (2000) 347-355.

29 Baddoo, N. and Hall, T.: Motivators of software process improvement: An analysis of practitioner's views, Journal of Systems and Software (62). (2002) 85-96.

30 Coolican, H.: Research Methods and Statistics in Psychology. Hodder and Stoughton, London.(1999).

31 Butler, K.: The economics benefits of software process improvement, CrossTalk (July). (1995) 14-17.

32 Ashrafi, N.: The impact of software process improvement on quality: in theory and practice, Information \& Management 40 (7). (2003) 677-690.

33 Jiang, J., Klein, G., Hwang, H.-G., Huang, J. and Hung, S.-y.: An exploration of the relationship between software development process maturity and project performance, Information \& Management (41). (2004) 279-288.

34 SEI: Process Maturity Profile. Software Engineering Institute Carnegie Mellon University, (2004).

35 Rockart, J. F.: Chief executives define their own data needs, Harvard Business Review (2). (1979) 81-93.

36 Niazi, M., Wilson, D. and Zowghi, D.: A Framework for Assisting the Design of Effective Software Process Improvement Implementation Strategies, Journal of Systems and Software Vol 78 (2). (2005) 204-222.

37 Niazi, M., Wilson, D. and Zowghi, D.: A Maturity Model for the Implementation of Software Process Improvement: An empirical study, Journal of Systems and Software 74 (2). (2005) 155-172.

Appendix A: Participant Company Information

\begin{tabular}{llllll}
\hline Company & Scope & Age (yrs) & Size & $\begin{array}{l}\text { Software } \\
\text { size }\end{array}$ & $\begin{array}{l}\text { SPI in } \\
\text { operation (yrs) }\end{array}$ \\
\hline
\end{tabular}




\begin{tabular}{llllll}
\hline 1 & Australian & 3 & 38 & 14 & $<1$ \\
2 & Multi-national & $21-50$ & $>2000$ & $\mathrm{DK}$ & $>5$ \\
3 & Multi-national & $>50$ & $>2000$ & $101-500$ & $>5$ \\
4 & Multi-national & $11-20$ & $>2000$ & $501-2000$ & $1-2$ \\
5 & Australian & $6-10$ & $<10$ & $<10$ & $>5$ \\
6 & Australian & $21-50$ & $11-100$ & 30 & $3-5$ \\
7 & Multi-national & $21-50$ & $>2000$ & $\mathrm{DK}$ & $>5$ \\
8 & Multi-national & $>50$ & $501-2000$ & $26-100$ & $>5$ \\
9 & Multi-national & $>50$ & $>2000$ & $>2000$ & $>5$ \\
10 & Australian & $>50$ & $101-500$ & $11-25$ & $3-5$ \\
11 & Multi-national & $>50$ & $>2000$ & $>2000$ & $3-5$ \\
12 & Australian & $<5$ & $<10$ & $<10$ & $1-2$ \\
13 & Multi-national & $>50$ & $>2000$ & DK & $>5$ \\
14 & Multi-national & $11-20$ & $>2000$ & $>2000$ & $3-5$ \\
15 & Australian & $21-50$ & $>2000$ & $101-500$ & $1-2$ \\
16 & Multi-national & $21-50$ & $>2000$ & $>2000$ & $>5$ \\
17 & Multi-national & $11-20$ & $>2000$ & $11-25$ & $>5$ \\
18 & Multi-national & $>50$ & $>2000$ & $101-500$ & $>5$ \\
19 & Australian & $11-20$ & $11-100$ & $11-25$ & $1-2$ \\
20 & Australian & $21-50$ & $>2000$ & DK & $>5$ \\
21 & Multi-national & $<5$ & $11-100$ & $11-25$ & $1-2$ \\
22 & Australian & $11-20$ & $11-100$ & $11-25$ & $3-5$ \\
23 & Multi-national & $6-10$ & $101-500$ & $26-100$ & $3-5$ \\
24 & Australian & $<5$ & $<10$ & $<10$ & $3-5$ \\
25 & Australian & $6-10$ & $>2000$ & $101-500$ & $>5$ \\
26 & Australian & $6-10$ & $11-100$ & $26-100$ & $>5$ \\
27 & Australian & $>50$ & $101-500$ & $<10$ & $1-2$ \\
28 & Multi-national & $>50$ & $>2000$ & $11-25$ & $>5$ \\
29 & Multi-national & $>50$ & $>2000$ & $501-2000$ & $>5$ \\
\hline
\end{tabular}

